\title{
Thermodynamic Analysis of the Low- to Physiological-Temperature Nondenaturational Conformational Change of Bovine Carbonic Anhydrase
}

\author{
Heather N. Hollowell, Saronya S. Younvanich, Stacey L. McNevin and B. Mark Britt* \\ Department of Chemistry and Physics, Texas Woman's University, Denton, TX 76204, USA
}

Received 15 September 2006, Accepted 17 October 2006

The stability curve - a plot of the Gibbs free energy of unfolding versus temperature - is calculated for bovine erythrocyte carbonic anhydrase in $150 \mathrm{mM}$ sodium phosphate $(\mathrm{pH}=7.0)$ from a combination of reversible differential scanning calorimetry measurements and isothermal guanidine hydrochloride titrations. The enzyme possesses two stable folded conformers with the conformational transition occurring at $\sim 30^{\circ} \mathrm{C}$. The methodology yields a stability curve for the complete unfolding of the enzyme below this temperature but only the partial unfolding, to the molten globule state, above it. The transition state thermodynamics for the low- to physiological-temperature conformational change are calculated from slow-scan-rate differential scanning calorimetry measurements where it is found that the free energy barrier for the conversion is 90 $\mathrm{kJ} / \mathrm{mole}$ and the transition state possesses a substantial unfolding quality. The data therefore suggest that the $x$-ray structure may differ considerably from the physiological structure and that the two conformers are not readily interconverted.

Keywords: Arrhenius, Bimodal stability curve, Bovine carbonic anhydrase, Slow-scan-rate DSC, Thermodynamics

\section{Introduction}

It is generally assumed that enzyme structures determined by traditional methods are the physiological structures though $\mathrm{x}$ ray diffraction and NMR techniques are typically performed below organismal optimal thriving temperatures. The x-ray structure analysis of bovine erythrocyte carbonic anhydrase (BCA), for example, was performed on crystals formed at $18^{\circ} \mathrm{C}$ (Eriksson and Liljas, 1986), well below the bovine normal

\footnotetext{
*To whom correspondence should be addressed.

Tel: 940-898-2566; Fax: 940-898-2548

E-mail: mbritt@twu.edu
}

body temperature of $38.3^{\circ} \mathrm{C}$. Evidence for a temperatureinduced conformational change in the enzyme between these temperatures exists in the form of a nonlinear Arrhenius plot in enzyme activity (Sarraf et al., 2004). If it can be demonstrated that a substantial conformational change occurs in the enzyme between these temperatures then it would strongly suggest that the x-ray structure cannot be the physiological structure. We have recently demonstrated that this is the case with another bovine enzyme, adenosine deaminase, where it was found that a substantial conformational change occurs at $29^{\circ} \mathrm{C}$ (Anderson and Britt, 2002) and the free energy activation barriers for the interconversion of the two conformers are very high (Bodnar and Britt, 2006).

There are reasons to suspect that the existence of two folded forms may be a general feature of enzyme structure given the dual functional requirements of substrate binding and chemical conversion (Britt, 2004). We report here the discovery of a nondenaturational conformational change in BCA by two independent methods. The calculated stability curve - a plot of the temperature dependence of the free energy of unfolding-of BCA is bimodal and reveals a conformational transition at $\sim 30^{\circ} \mathrm{C}$. The same transition temperature is revealed by slow-scan-rate differential scanning calorimetry where the free energy of activation for the conversion of the low-temperature conformer to the physiologicaltemperature conformer is revealed to be very high and that for the reverse change even higher. Standard thermodynamic analysis of the low- to physiological-temperature conformational change transition state reveals a substantial unfolding quality.

The stability curve is calculated in two parts by two different methods. The physiological conformer stability curve is calculated from thermodynamic parameters obtained from reversible unfoldings in the presence of guanidine hydrochloride $(\mathrm{GuHCl})$ extrapolated to zero concentration denaturant as measured by differential scanning calorimetry (DSC). We have recently successfully applied this approach to hen egg white lysozyme (Younvanich and Britt, 2006). BCA is well known to unfold via a four-state process so extra care must be taken to identify the final state for each of the two methods. 
We argue that the physiological stability curve reflects only the unfolding from the native state to the first intermediate state, namely the molten globule state.

The low-temperature portion of the curve is obtained from standard isothermal titrations with $\mathrm{GuHCl}$. Analysis suggests that this portion of the stability curve reflects the complete unfolding of the enzyme.

The transition state thermodynamics for the conversion of the low-temperature conformer to the physiological-temperature conformer are obtained from slow-scan-rate DSC (Bodnar and Britt, 2006).

\section{Materials and Methods}

Bovine carbonic anhydrase (product number C3934), GuHCl, and the sodium phosphate buffer components were obtained from Sigma Chemical Company. All measurements were performed in $150 \mathrm{mM}$ sodium phosphate, $\mathrm{pH}=7.0$. Calorimetric measurements were made on a Calorimetry Sciences Corporation Nano Series III instrument.

To obtain data for the physiological temperature portion of the stability curve, BCA solutions were prepared in buffer and then allowed to dialyze for at least $72 \mathrm{~h}$ against either $0.37,1.10,1.56$, or $2.10 \mathrm{M}$ solutions of $\mathrm{GuHCl}$ in a cold room. Exact $\mathrm{GuHCl}$ concentrations were determined from the solution refractive index (Nozaki, 1972). After dialysis the BCA concentration was determined by diluting a $10 \mu \mathrm{l}$ aliquot to $2,010 \mu \mathrm{l}$ in $6.0 \mathrm{M} \mathrm{GuHCl}$, allowing the solution to sit overnight, and then determining the concentration using a value of $\varepsilon_{280}=50,070 \mathrm{M}^{-1} \mathrm{~cm}^{-1}$ (Gill and von Hippel, 1989). The DSC runs employed degassed $2.0 \mathrm{mg} / \mathrm{ml}$ solutions and a scan rate of $0.5^{\circ} \mathrm{C} / \mathrm{min}$. All runs were baseline corrected at the same scan rate with a run of dialysate vs. dialysate. The reversibility at each $[\mathrm{GuHCl}]$ was checked by preparing a new sample, scanning just up to the unfolding temperature, allowing the system to sit at $8^{\circ} \mathrm{C}$ for at least a couple of hours, and then repeating the scan up to the transition temperature. The two higher concentration runs were completely reversible while the two lower concentration runs were only partly so. To accommodate for only partial reversibility all curves were analyzed by modeling a two-state transition as provided by the instrument software but fitting only just over the transition as is sometimes done with known partially irreversible systems. Analysis with more complex models did not yield better fits. The results of analysis were values of the enthalpy of unfolding $\Delta \mathrm{H}_{\mathrm{u}}$ and the temperature of unfolding $\mathrm{T}_{\mathrm{u}}$ as functions of [ $\left.\mathrm{GuHCl}\right]$.

The low-temperature portion of the stability curve was calculated from isothermal $\mathrm{GuHCl}$ titrations. $\mathrm{GuHCl}$ titrations were performed at 5.0, 7.5, 10.0, 15.0, and $20.0^{\circ} \mathrm{C}$ on a SPEX Fluoromax-3 spectrometer equipped with a Wavelength Electronics Peltier temperature controller. Comparison of the fluorescence emission spectra of a $10 \mu \mathrm{M}$ solution of the enzyme in buffer (folded) and of a $10 \mu \mathrm{M}$ solution in $6 \mathrm{M} \mathrm{GuHCl}$ (unfolded) with excitation at 280 $\mathrm{nm}$ revealed that $317 \mathrm{~nm}$ was the best emission wavelength to observe the transition. Samples were $5 \mu \mathrm{M}$ in enzyme and prepared using stock solutions of highly concentrated $\mathrm{GuHCl}$ and of buffer. Samples incubated in a water bath at temperature for at least $72 \mathrm{~h}$.

The fraction of enzyme unfolded $f_{u}$ at any $[\mathrm{GuHCl}]$ is $f_{u}=[\mathrm{U}] /$
$([\mathrm{N}]+[\mathrm{U}])$ where $[\mathrm{U}]$ is the concentration of unfolded enzyme and $[\mathrm{N}]$ is the concentration of native enzyme. The unfolding of the enzyme was revealed by a sharp drop in the fluorescence emission. Values of $f_{u}$ were calculated by first modeling both the pre- and post-transitions with linear fits $\left(l_{\text {pre }}\right.$ and $\left.l_{\text {post }}\right)$. Modelling with higher order polynomials did not improve the fit quality. Values of $f_{u}$ as a function of $[\mathrm{GuHCl}]$ were calculated from $\mathrm{f}_{\mathrm{u}}=\left(1_{\text {pre }}-\mathrm{f}\right) /\left(1_{\text {pre }}-1_{\text {post }}\right)$ where $\mathrm{f}$ is the fluorescence emission value in the transition region.

Defining the equilibrium constant for unfolding at any [GuHCl] as $\mathrm{K}=[\mathrm{U}] /[\mathrm{N}]$ the fraction unfolded becomes $\mathrm{f}_{\mathrm{u}}=1 /(1+1 / \mathrm{K})$. We assume that the unfolding free energy in the presence of $\mathrm{GuHCl}$, $\Delta \mathrm{G}_{\mathrm{u}(\mathrm{GuHCl})}$, is related linearly to the physiological free energy of unfolding $\Delta \mathrm{G}_{\mathrm{u}}$ by $\Delta \mathrm{G}_{\mathrm{u}(\mathrm{GuHCl})}=\Delta \mathrm{G}_{\mathrm{u}}-\mathrm{m}[\mathrm{GuHCl}]$ where $\mathrm{m}$ is a fitting parameter (Greene and Pace, 1974). Working from the relationship $\Delta \mathrm{G}_{\mathrm{u}}=-\mathrm{RT}[\ln (\mathrm{K})]$ it can be shown that $\mathrm{f}_{\mathrm{u}}=1 /\left(1+\exp \left(\left(\Delta \mathrm{G}_{\mathrm{u}}-\right.\right.\right.$ $\mathrm{m}[\mathrm{GuHCl}] / \mathrm{RT})$ ). Data were modeled with this equation using Microcal Origin software to obtain $\Delta \mathrm{G}_{\mathrm{u}}$ as a function of temperature.

For the determination of the transition state thermodynamics for the low- to physiological-temperature conformational change, a stock solution of BCA was dialyzed against a thousand-fold excess of buffer for at least $36 \mathrm{~h}$. The concentration of the resulting solution was determined as above. BCA solutions for the DSC scans were $5.0 \mathrm{mg} / \mathrm{ml}$ and prepared from dilution with dialysate. All sample scans were corrected with runs of dialysate versus dialysate at the same scan rates as the sample runs. Scan rates were $0.020,0.030,0.060,0.070$, and $0.10^{\circ} \mathrm{C} / \mathrm{min}$. The conformational change from the low- to physiological-temperature conformer is indicated by a sharp increase in heat capacity. First order rate constants $\left(\mathrm{k}_{1}\right)$ for the conversion of the low-temperature conformer to the physiological-temperature conformer were calculated from $\mathrm{k}_{1}$ $=\mathrm{r}_{\text {scan }} / \Delta \mathrm{T}$ at $\mathrm{T}_{\mathrm{t}}$ where $\Delta \mathrm{T}$ is the temperature interval of the transition centered about the transition temperature $T_{t}$ (Bodnar and Britt, 2006). The transition state thermodynamics are calculated at $30^{\circ} \mathrm{C}$, the temperature of the nondenaturational conformational change.

\section{Results and Discussion}

The complete unfolding of several carbonic anhydrases including BCA is known to occur via a molten globule state (Uversky et al., 1992; Martensen et al., 1993; Uversky and Ptitsyn, 1996; Kutyshenko and Prokhorov, 2003; Kjellson et al., 2003; Prokhorov et al., 2005). Uversky and Ptitsyn provide evidence for a four-state unfolding event where the folded or native enzyme $\mathrm{N}$ first unfolds to a molten globule state $\mathrm{MG}$, then to a pre-molten globule state (from the folding perspective) $\mathrm{PG}$, and then finally to the true unfolded state U. For the present study we are interested in establishing an ambient temperatureinduced conformational change in the enzyme that is associated with a high activation energy barrier for the conversion from the low-temperature conformer to the physiological-temperature conformer. A stability curve - a plot of the physiological free energy of unfolding $\Delta \mathrm{G}_{\mathrm{u}}$ versus temperature (Becktel and Schellman, 1987)-offers a convenient way of not only establishing the existence of a temperature-induced change in enzyme conformation but also affording a means for comparison of the equilibrium unfolding thermodynamics. A direct 


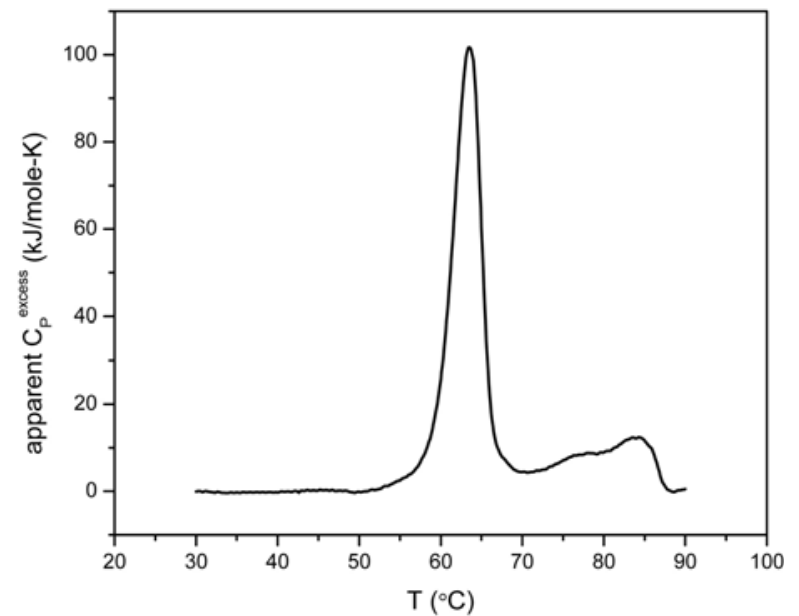

Fig. 1. DSC trace of $B C A$ in $150 \mathrm{mM}$ phosphate $(\mathrm{pH}=7.0)$ consistent with the existence of a four-state unfolding event (Uversky and Ptitsyn, 1996).

comparison may be made if each conformer unfolds to the same final state. However, it is not clear from the outset whether the two different techniques employed here for this particular enzyme explore the same final state. It is therefore first necessary to establish the identities of the final states for either technique.

Figure 1 shows a DSC scan of a $4 \mathrm{mg} / \mathrm{ml}$ sample of BCA. What appear to be at least three unfolding events are clearly discernible in support of a proposed model (Uversky and Ptitsyn, 1996). This scan is qualitatively very similar to that of bovine serum fetuin which apparently unfolds via a single intermediate molten globule state (Wang et al., 1998). It will be shown that the general shape of this DSC curve and the analysis of the transition temperature trend of the reversible DSC data strongly suggests that we are examining the unfolding of the physiological-temperature conformer to the molten globule state. Further analysis of Figure 1 is beyond the scope of this work.

For the calculation of the stability curve of the low-temperature conformer we employ standard isothermal $\mathrm{GuHCl}$ titrations. Figure 2 shows the results of our $\mathrm{GuHCl}$ titrations of the enzyme. All transitions are well modeled as two-state processes where the initial state is the native enzyme. Attempts to model the titration data with more complex models involving an unfolding intermediate or the concurrent unfolding of two different states did not improve the quality of the fits.

While the initial state is clearly the native enzyme the identity of the final state is not obvious from these data. In consideration of the possibility that the titrations shown in Fig. 2 are examining only a portion of the complete unfolding we perform an additional titration over a much wider $\mathrm{GuHCl}$ concentration range (Fig. 3) where we assume the gross fluorescence emission of the enzyme is likely to change beween any two states. Figure 3 suggests that there is only

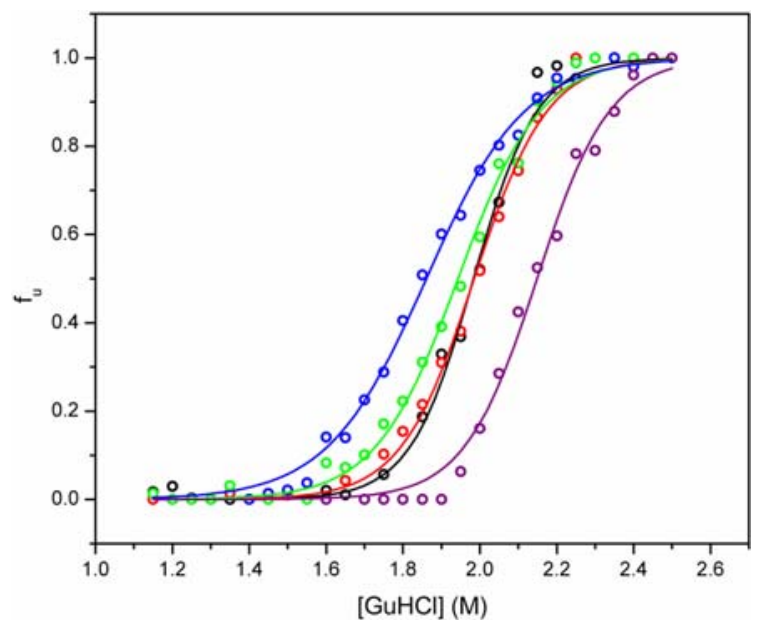

Fig. 2. $\mathrm{GuHCl}$ titrations at $5.0^{\circ} \mathrm{C}$ (black), $7.5^{\circ} \mathrm{C}$ (purple) $10.0^{\circ} \mathrm{C}$ (red), $15.0^{\circ} \mathrm{C}$ (green), and $20.0^{\circ} \mathrm{C}$ (blue). Also shown are fits of the data to $\mathrm{f}_{\mathrm{u}}=1 /\left(1+\exp \left(\left(\Delta \mathrm{G}_{\mathrm{u}}-\mathrm{m}[\mathrm{GuHCl}]\right) / \mathrm{RT}\right)\right)$ to yield physiological values of $\Delta \mathrm{G}_{\mathrm{u}}$.

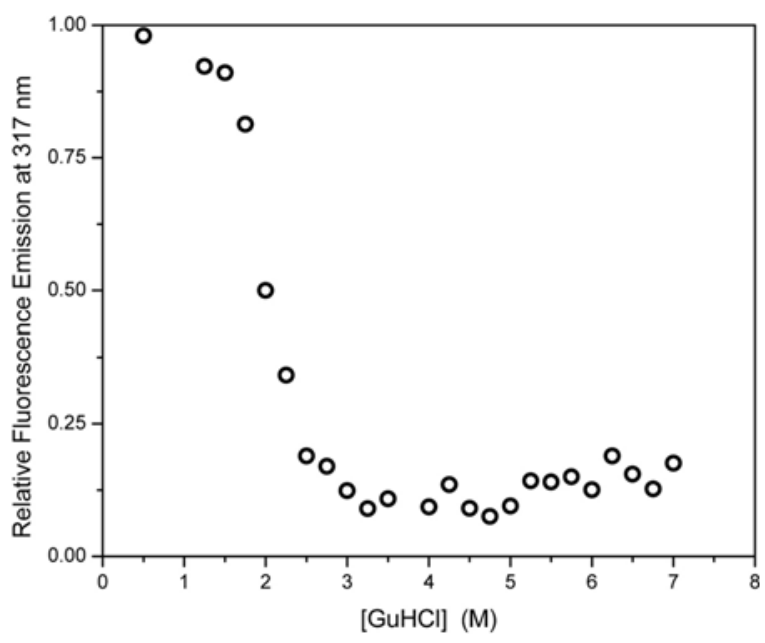

Fig. 3. Unfolding titration of $\mathrm{BCA}$ at $7.5^{\circ} \mathrm{C}$.

one observable event and that this event has significant contributions from only the native $\mathrm{N}$ and unfolded $\mathrm{U}$ states. The stability curve thus generated for the low-temperature enzyme conformation reflects the complete unfolding of the enzyme UU.

The stability curve of an enzyme is defined as a plot of the free energy of unfolding versus temperature and is given by (Becktel and Schellman, 1987)

$$
\Delta \mathrm{G}_{\mathrm{u}}=\Delta \mathrm{H}_{\mathrm{u}}\left(1-\mathrm{T} / \mathrm{T}_{\mathrm{u}}\right)+\Delta \mathrm{C}_{\mathrm{P}}\left(\mathrm{T}-\mathrm{T}_{\mathrm{u}}-\mathrm{T}\left(\ln \left(\mathrm{T} / \mathrm{T}_{\mathrm{u}}\right)\right)\right)
$$

where $\Delta \mathrm{H}_{\mathrm{u}}$ is the unfolding enthalpy change at the reference (unfolding) temperature $T_{u}$ and $\Delta C_{P}$ is the unfolding heat capacity change. Values of $T_{u}, \Delta H_{u}$, and $\Delta C_{P}$ for each conformer must therefore be determined to construct the curve.

The physiological-temperature regime of the curve is calculated from linear extrapolations to physiological conditions 


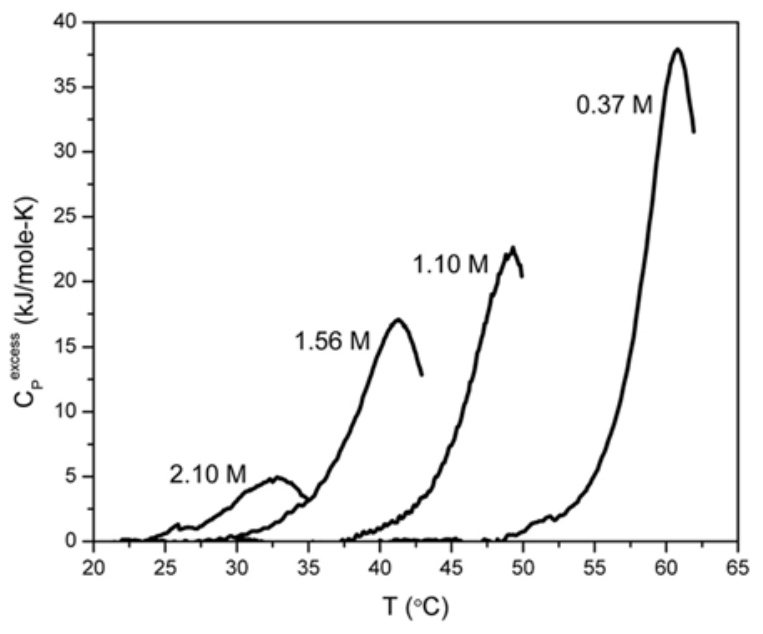

Fig. 4. DSC scans of the transition of $\mathrm{BCA}$ from the native to molten globule state as a function of $[\mathrm{GuHCl}]$.

of thermodynamic values obtained from DSC measurements from reversible conditions; i.e., in the presence of $\mathrm{GuHCl}$. This is necessary because the typical irreversibility of thermal unfolding of enzymes under physiological conditions renders thermodynamic analysis impossible. This analysis assumes, if a nondenaturational conformational change occurs at ambient temperature only the higher temperature conformation is observed. It will later be demonstrated, with consideration of the kinetics of the conformational change, that this is a valid approach. We have recently applied this methodology in the calculation of the stability curve of hen egg white lysozyme (Younvanich and Britt, 2006).

Figure 4 shows DSC scans of the unfolding of BCA over a wide range of $\mathrm{GuHCl}$ concentrations. These curves have the general shape of the first transition shown in Fig. 1. Inspection of the scans reveals the temperature of unfolding $T_{u}$ and the enthalpy of unfolding $\Delta \mathrm{H}_{\mathrm{u}}$ both decrease with increasing

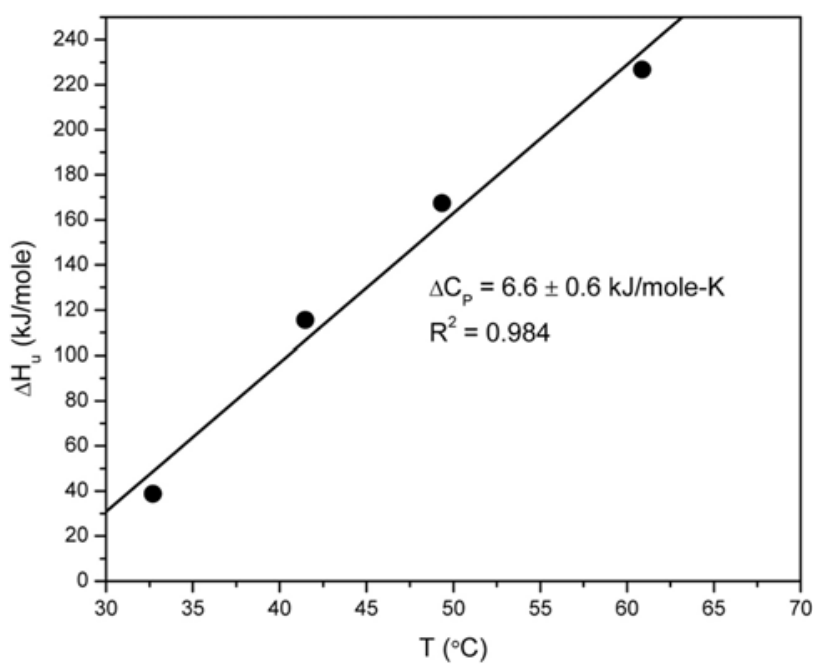

Fig. 6. Calculation of $\Delta C_{P}$ for the unfolding of the physiologicaltemperature conformation of BCA.

[GuHCl] as a result of the destabilizing influence of the denaturant. Analysis reveals the following thermodynamic values for $\mathrm{T}_{\mathrm{u}}$ and $\Delta \mathrm{H}_{\mathrm{u}}$ as a function of [GuHCl] : [GuHCl$]=$ $0.37 \mathrm{M}, \mathrm{T}_{\mathrm{u}}=60.88^{\circ} \mathrm{C}, \Delta \mathrm{H}_{\mathrm{u}}=226.7 \mathrm{~kJ} / \mathrm{mole} ;[\mathrm{GuHCl}]=1.10$ $\mathrm{M}, \mathrm{T}_{\mathrm{u}}=49.35^{\circ} \mathrm{C}, \Delta \mathrm{H}_{\mathrm{u}}=167.5 \mathrm{~kJ} / \mathrm{mole} ;[\mathrm{GuHCl}]=1.56 \mathrm{M}, \mathrm{T}_{\mathrm{u}}$ $=41.47^{\circ} \mathrm{C}, \Delta \mathrm{H}_{\mathrm{u}}=115.6 \mathrm{~kJ} / \mathrm{mole} ; \quad[\mathrm{GuHCl}]=2.10 \mathrm{M}, \quad \mathrm{T}_{\mathrm{u}}=$ $32.70^{\circ} \mathrm{C}, \Delta \mathrm{H}_{\mathrm{u}}=38.8 \mathrm{~kJ} / \mathrm{mole}$.

Physiological values for $T_{u}$ and $\Delta H_{u}$ are obtained from linear extrapolations to zero concentration $\mathrm{GuHCl}$ as shown in Fig. 5. By this analysis, $\mathrm{T}_{\mathrm{u}}=67.4 \pm 0.2^{\circ} \mathrm{C}$ and $\Delta \mathrm{H}_{\mathrm{u}}=275 \pm 15 \mathrm{~kJ} /$ mole. This value of $T_{u}$ compares to a value for an apparent $T_{u}$ of $63.5^{\circ} \mathrm{C}$ for the conversion of the native enzyme to, presumably, the molten globule state as revealed by the scan shown in Fig. 1. $\Delta \mathrm{C}_{\mathrm{P}}$ is calculated from $\Delta\left(\Delta \mathrm{H}_{\mathrm{u}}\right) / \Delta \mathrm{T}$ (Fig. 6). $\Delta \mathrm{C}_{\mathrm{P}}=6.6 \pm 0.6 \mathrm{~kJ} / \mathrm{mole}-\mathrm{K}$. These parameters are used to calculate from eq. 1 the physiological-temperature region of the stability
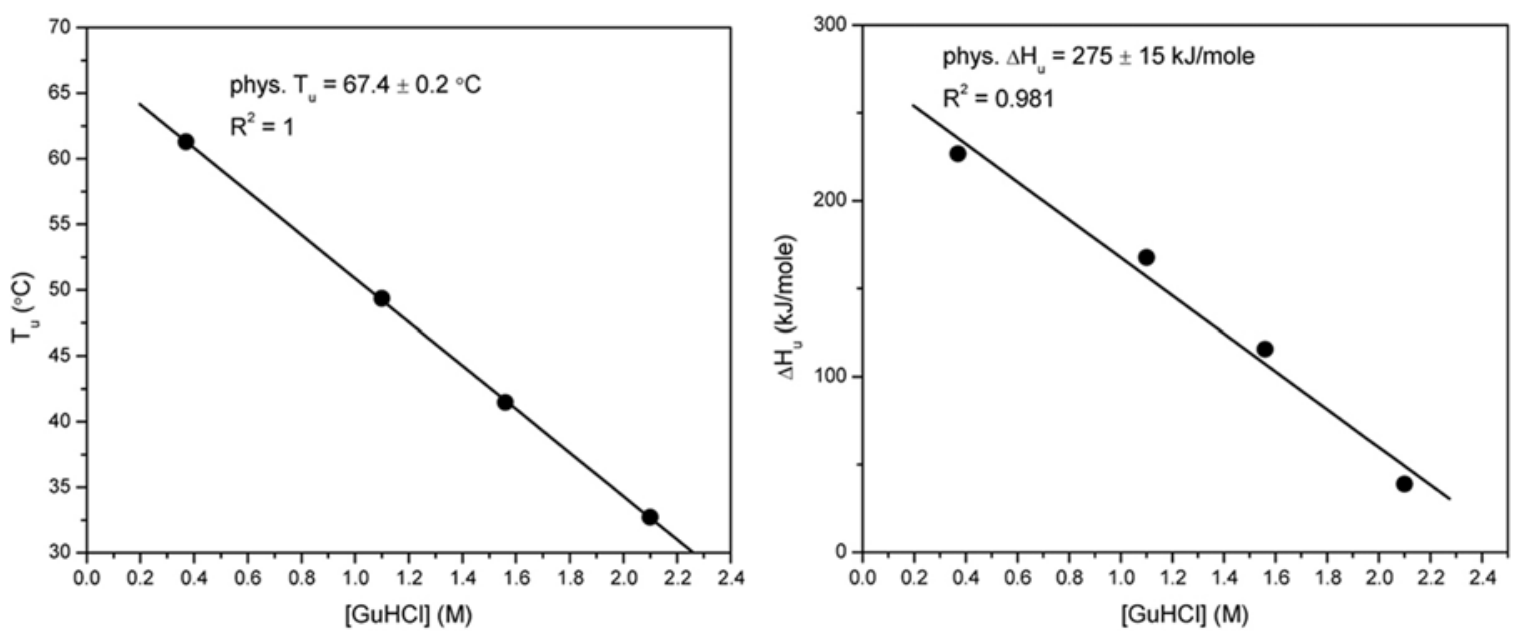

Fig. 5. Plots of $T_{u}$ and $\Delta H_{u}$ as a function of [GuHCl] as determined from analysis of DSC scans. Linear extrapolations yield the physiological values indicated. 


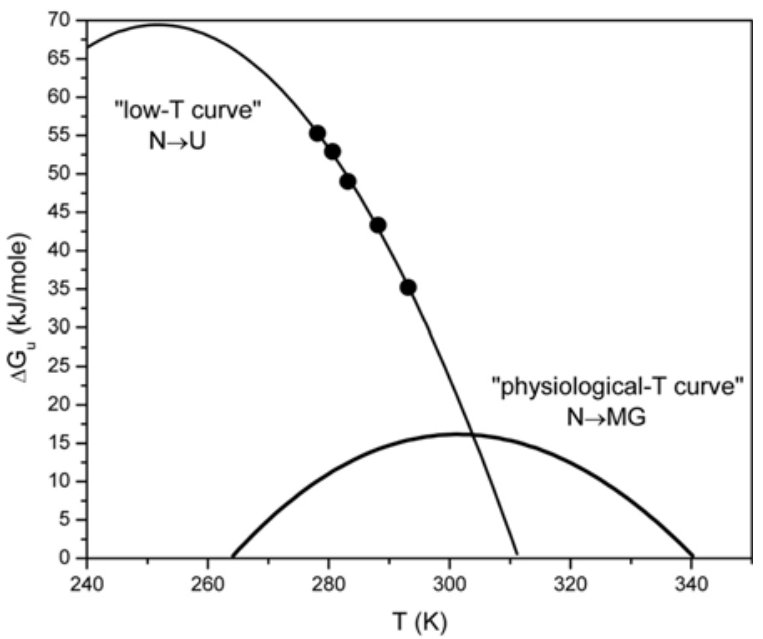

Fig. 7. Physiological, bimodal stability curve of BCA in 150 $\mathrm{mM}$ phosphate $(\mathrm{pH}=7.0)$. The low-temperature curve reflects the complete unfolding of the enzyme while the physiologicaltemperature curve reflects only the unfolding from the native state to the molten globule state. The physiological conformer stability curve is described by $\mathrm{T}_{\mathrm{u}}=67.4 \pm 0.2^{\circ} \mathrm{C}, \Delta \mathrm{H}_{\mathrm{u}}=275 \pm 15$ $\mathrm{kJ} / \mathrm{mole}$, and $\Delta \mathrm{C}_{\mathrm{P}}=6.6 \pm 0.6 \mathrm{~kJ} / \mathrm{mole}-\mathrm{K}$. The low-temperature conformer stability curve is described by $\mathrm{T}_{\mathrm{u}}=38.3 \pm 3.0^{\circ} \mathrm{C}, \Delta \mathrm{H}_{\mathrm{u}}$ $=701 \pm 123 \mathrm{~kJ} / \mathrm{mole}$, and $\Delta \mathrm{C}_{\mathrm{P}}=10.6 \pm 6.0 \mathrm{~kJ} / \mathrm{mole}-\mathrm{K}$.

\section{curve shown in Fig. 7.}

Next, we calculate the low-temperature portion of the stability curve. This is done by determining physiological values of $\Delta \mathrm{G}_{\mathrm{u}}$ via the $\mathrm{GuHCl}$ titrations at a few temperatures and then modeling these values with eq. 1. Figure 2 shows our titrations of BCA. Analysis yields the following values of physiological $\Delta \mathrm{G}_{\mathrm{u}} \mathrm{s}: 5.0^{\circ} \mathrm{C}, \Delta \mathrm{G}_{\mathrm{u}}=55.3 \pm 3.4 \mathrm{~kJ} / \mathrm{mole} ; 7.5^{\circ} \mathrm{C}$, $\Delta \mathrm{G}_{\mathrm{u}}=52.9 \pm 3.5 \mathrm{~kJ} / \mathrm{mole} ; 10.0^{\circ} \mathrm{C}, \Delta \mathrm{G}_{\mathrm{u}}=49.0 \pm 1.2 \mathrm{~kJ} / \mathrm{mole}$; $15.0^{\circ} \mathrm{C}, \Delta \mathrm{G}_{\mathrm{u}}=43.3 \pm 1.7 \mathrm{~kJ} / \mathrm{mole} ; 20.0^{\circ} \mathrm{C}, \Delta \mathrm{G}_{\mathrm{u}}=35.2 \pm 1.4$ $\mathrm{kJ} / \mathrm{mole}$. Fitting these data to eq. 1 yields the stability curve for the low-temperature conformer (Fig. 7) described by $\mathrm{T}_{\mathrm{u}}=$ $38.3 \pm 3.0^{\circ} \mathrm{C}, \Delta \mathrm{H}_{\mathrm{u}}=701 \pm 123 \mathrm{~kJ} / \mathrm{mole}$, and $\Delta \mathrm{C}_{\mathrm{P}}=10.6 \pm 6.0$ $\mathrm{kJ} /$ mole-K.

The resultant stability curve implies a nondenaturational enzyme conformational change at a temperature indicated by the point of intersection of the two curves, namely $\sim 31^{\circ} \mathrm{C}$. Though a straightforward thermodynamic comparison of the two curves is impossible due to the different final states probed, these data strongly suggest the x-ray structure may be substantially different from the physiological structure. The influence on catalysis of the existence of a different conformation outside the physiological regime has previously been discussed (Britt, 2004).

Also unlike the bimodal stability curve of bovine adenosine deaminase (Anderson and Britt, 2002) there is a considerable temperature overlap of the two conformers. It is therefore reasonable to ask whether the modeling of the titrations shown in Fig. 2 should be more complex than the methodology we employ. This can be addressed by considering the ratio of the

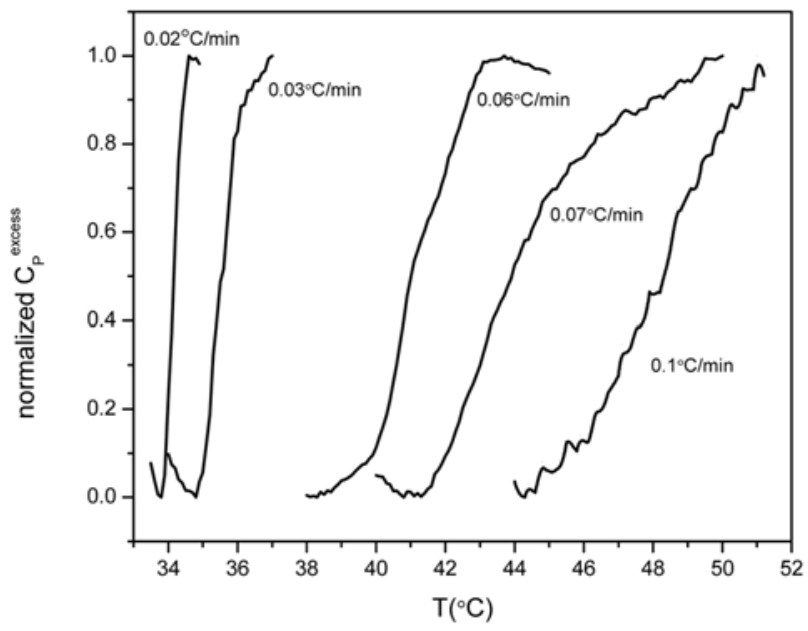

Fig. 8. Slow-scan-rate DSC scans revealing the relative increase in excess heat capacity as the BCA transitions from the lowtemperature conformer to the physiological conformer. Scans are normalized and show portions of the pre- and post-transitions used in analysis. The scan rates are indicated.

low-temperature conformer $\mathrm{L}$ concentration to that of the physiological-temperature conformer $\mathrm{P}([\mathrm{L}] /[\mathrm{P}])$ at a given temperature. This value may be roughly estimated from the stability curve by calculating the ratio of the unfolding equilibrium constants of the two conformers where under phyiological conditions $K_{\mathrm{P}}=[\mathrm{MG}] /[\mathrm{P}]$ and under lowtemperature conditions $\mathrm{K}_{\mathrm{L}}=[\mathrm{U}] /[\mathrm{L}]$. If it is assumed that the thermodynamic difference between $\mathrm{MG}$ and $\mathrm{U}$ is small compared to the thermodynamic differences between $\mathrm{N}$ and MG (and therefore between $\mathrm{N}$ and $\mathrm{U}$ ), an assumption supported by Fig. 1, then a rough estimate for $[\mathrm{L}] / \mathrm{P}]$ is $\mathrm{K}_{\mathrm{P}} / \mathrm{K}_{\mathrm{L}}$ at the temperature of interest. At $20.0^{\circ} \mathrm{C}$, the titration temperature where a mixture of the two is most likely to be encountered, $[\mathrm{L}] /[\mathrm{P}]=\exp \left[\left(\Delta \mathrm{G}_{\mathrm{u}}^{\mathrm{L}}-\Delta \mathrm{G}_{\mathrm{u}}{ }^{\mathrm{P}}\right) / \mathrm{RT}\right]=\exp [(35.2 \mathrm{~kJ} /$ mole $-15.4 \mathrm{~kJ} / \mathrm{mole}) /(2.44 \mathrm{~kJ} / \mathrm{mole})]=\mathrm{e}^{8.11} \approx 3300$. At $20^{\circ} \mathrm{C}$, and for all other titration temperatures, the contribution of the physiological conformer to the overall concentration is therefore negligible. It is therefore appropriate to model the titration curves as involving only one transition.

To understand the transition state thermodynamics of the low- to physiological-temperature conformational change we consider the transition is likely to be under kinetic control, as we have observed in bovine adenosine deaminase, and therefore employ slow-scan-rate DSC (Bodnar and Britt, 2006).

Figure 8 shows the results of a series of scans of BCA under physiological conditions $(150 \mathrm{mM}$ buffer, $\mathrm{pH}=7)$. These scans differ from conventional DSC scans in that there is no apparent enthalpy component. This may be attributed to the very slow scan rates employed here. Heat effects associated with the conformational change occur over a very long time period and go undetected by the instrument. Scanning at the conventional scan rate of $1^{\circ} \mathrm{C} / \mathrm{min}$ does not reveal the transition. These scans are reversible in the sense that if each 
Table 1. DSC scan characteristics of the runs shown in Fig. 7

\begin{tabular}{cccc}
\hline $\mathrm{r}_{\text {scan }}\left({ }^{\circ} \mathrm{C} / \mathrm{min}\right)$ & $\mathrm{T}_{\mathrm{t}}\left({ }^{\circ} \mathrm{C}\right)$ & $\Delta \mathrm{T}\left({ }^{\circ} \mathrm{C}\right)$ & $\mathrm{k}\left(\mathrm{s}^{-1}\right)$ \\
\hline 0.020 & 34.12 & 0.60 & $5.56 \times 10^{-4}$ \\
0.030 & 35.38 & 1.04 & $4.81 \times 10^{-4}$ \\
0.060 & 41.31 & 3.62 & $2.76 \times 10^{-4}$ \\
0.070 & 42.88 & 4.07 & $2.87 \times 10^{-4}$ \\
0.10 & 47.34 & 3.60 & $4.63 \times 10^{-4}$ \\
\hline
\end{tabular}

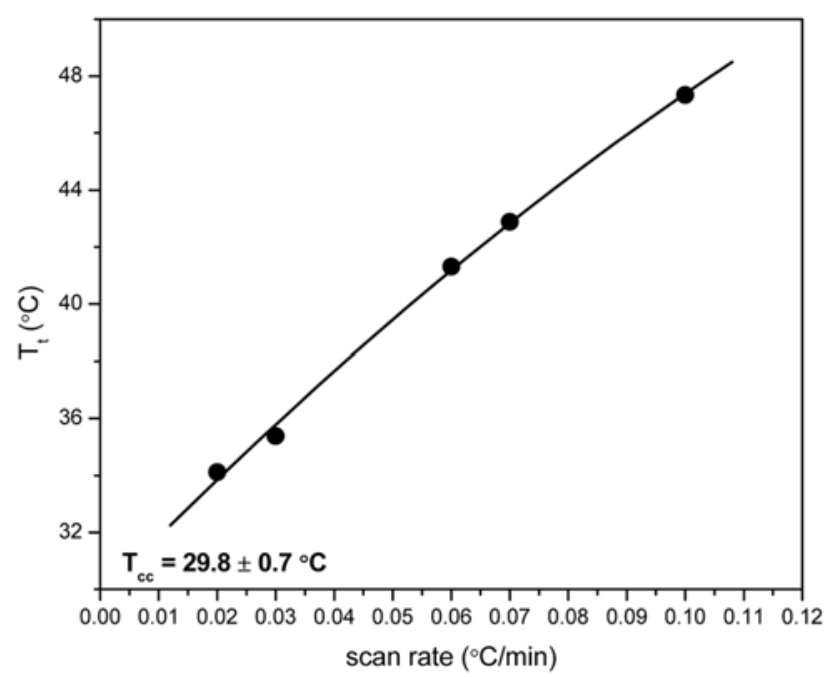

Fig. 9. $T_{t}$ versus scan rate trend for the low- to physiologicaltemperature conformational change. Shown also is a quadratic fit $\left(\mathrm{R}^{2}=0.997\right)$ to the data revealing $\mathrm{T}_{\mathrm{CC}}=29.8 \pm 0.7^{\circ} \mathrm{C}$ at zero scan rate.

solution used for the scan is recovered and kept at $4^{\circ} \mathrm{C}$ for over $72 \mathrm{~h}$ and a scan repeated a nearly identical trace is obtained. Waiting for only two days does not reproduce the result. Scanning from high to low temperature does not reveal a transition.

A clearly observable trend is for both the transition temperature $T_{t}$ and the transition temperature interval $\Delta T$ to generally increase with scan rate (Table 1). Figure 9 shows a plot of $T_{t}$ versus scan rate. The trend is well modeled by a quadratic and reveals a value of the conformational change temperature $\mathrm{T}_{\mathrm{CC}}=29.8 \pm 0.7^{\circ} \mathrm{C}$ at zero scan rate. This compares favorably with the value of $\sim 31^{\circ} \mathrm{C}$ ascertained from inspection of the stability curve (Fig. 6) and with the inflection temperature of the Arrhenius plot of enzyme activity (Sarraf et al., 2004). We consider the $\mathrm{T}_{\mathrm{CC}}$ determined by the slow-scanrate DSC method to be the more accurate value. We therefore calculate the transition state thermodynamics for the low- to physiological-temperature conformational change at $30^{\circ} \mathrm{C}$.

To calculate the transition state thermodynamics it is necessary to first construct an Arrhenius plot (Fig. 10). At $30^{\circ} \mathrm{C}$, an extrapolated value of $1.91 \times 10^{-3} \mathrm{~s}^{-1}$ for the first order rate constant describing the transition is obtained. We

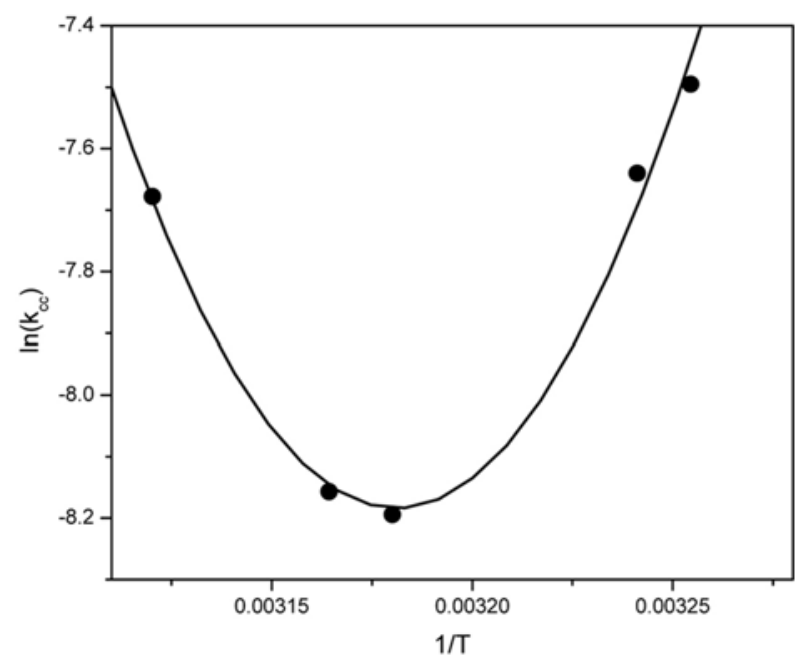

Fig. 10. Arrhenius plot of the rate constants from Table 1 describing the low- to physiological-temperature conformational change. The data trend is well modeled $\left(\mathrm{R}^{2}=0.988\right)$ by $\ln \left(\mathrm{k}_{\mathrm{cc}}\right)=$ $1.352 \times 10^{8}(1 / \mathrm{T})^{2}-8.599 \times 10^{5}(1 / \mathrm{T})+1359$.

calculate the activation free energy $\Delta \mathrm{G}$ from standard transition state theory where $\Delta \mathrm{G}=-\mathrm{RT}\left[\ln \left(\mathrm{kh} / \mathrm{k}_{\mathrm{B}} \mathrm{T}\right)\right]$ where $\mathrm{k}$ is the rate constant, $h$ is Planck's constant, and $\mathrm{k}_{\mathrm{B}}$ is Boltzmann's constant (Chen et al., 1989; Lopez-Arenas et al., 1999). $\Delta \mathrm{G}=$ $89.9 \mathrm{~kJ} / \mathrm{mole}$. This is a significant barrier to conformational change and is on the order of an unfolding event (Rendon and Mendoza-Hernandez, 2001; Strohmeyer et al., 2002).

The activation enthalpy $\Delta \mathrm{H}$ is calculated from $\Delta \mathrm{H}=\mathrm{E}_{\mathrm{a}}-$ RT where $E_{a}$ is the activation energy obtained from the slope (derivative) of the quadratic fit to the Arrhenius plot at $1 /$ $(303.2 \mathrm{~K})$. At $30^{\circ} \mathrm{C}, \Delta \mathrm{H}=-271 \mathrm{~kJ} / \mathrm{mole} . \Delta \mathrm{S}$ is calculated from $(\Delta \mathrm{H}-\Delta \mathrm{G}) / \mathrm{T}$ and is equal to $-1.19 \mathrm{~kJ} / \mathrm{mole}-\mathrm{K} . \Delta \mathrm{C}_{\mathrm{P}}$ is calculated from $\Delta(\Delta \mathrm{H}) / \Delta \mathrm{T}$ and is equal to $24.9 \mathrm{~kJ} / \mathrm{mole}-\mathrm{K}$. The signs and magnitudes of these thermodynamic parameters collectively point to a conformational change which consists of a substantial unfolding character. The magnitude of $\Delta \mathrm{C}_{\mathrm{P}}$ in particular points to a transition state structure with extensive ordering of water (Privalov, 1979; Privalov and Gill, 1988; Chen et al., 1989).

It is interesting to consider what a DSC scan at the conventional rate of $1^{\circ} \mathrm{C} / \mathrm{min}$ would reveal about the conformational change. At this scan rate, the trend in Fig. 9 indicates the conformational change does not occur until unfolding has begun. We may estimate a value for the first order rate constant from the trend shown in Fig. 9 at $340.6 \mathrm{~K}$, the temperature of thermal unfolding of BCA, of $0.93 \mathrm{~s}^{-1}$. We may then estimate the temperature interval $\Delta \mathrm{T}$ for the conformational transition at this temperature from $\Delta \mathrm{T}=\mathrm{r}_{\text {scan }} / \mathrm{k}_{1}$ (Bodnar and Britt, 2006). This analysis reveals that the conformational change would occur over only a $1.1^{\circ} \mathrm{C}$ interval. It is therefore doubtful whether the change could be discerned at a conventional scan rate. 


\section{Conclusions}

The stability curve of BCA consists of contributions from two folded conformers. Data from both equilibrium and transition state thermodynamic analysis reveals that the temperatureinduced conformational transition occurs at $\sim 30^{\circ} \mathrm{C}$. The free energy barrier for the temperature-induced conformational change from the low-temperature conformer to the physiologicaltemperature conformer is substantial at $89.9 \mathrm{~kJ} / \mathrm{mole}$. Further analysis of the other transition state thermodynamics suggests a significant unfolding quality in the conformational change transition state.

Acknowledgments This work was supported by a departmental grant from the Welch Foundation and an American Chemical Society Petroleum Research Fund grant.

\section{References}

Anderson, E. and Britt, B. M. (2002) The stability curve of bovine adenosine deaminase is bimodal. J. Biomol. Struct. Dynam. 20, 375-380.

Becktel, W. J. and Schellman, J. A. (1987) Protein stability curves. Biopolymers 26, 1859-1877.

Bodnar, M. A. and Britt, B. M. (2006) Transition state characterization of the low- to physiological-temperature nondenaturational conformational change in bovine adenosine deaminase by slow scan rate differential scanning calorimetry. J. Biochem. Mol. Biol. 39, 167-170.

Britt, B. M. (2004) Understanding enzyme structure and function in terms of the shifting specificity model. J. Biochem. Mol. Biol. 37, 394-401.

Chen, B., Baase, W. A. and Schellman, J. A. (1989) Lowtemperature unfolding of a mutant of phage T4 lysozyme 2. kinetic investigations. Biochemistry 28, 691-699.

Eriksson, E. A. and Liljas, A. (1986) Crystallization of and preliminary x-ray data for bovine carbonic anhydrase III. $J$. Biol. Chem. 261, 16247-16248.

Gill, S. C. and von Hippel, P. H. (1989) Calculation of protein extinction coefficients from amino acid sequence data. Anal. Biochem. 182, 319-326.

Greene, R. F. and Pace, C. N. (1974) Urea and guanidine hydrochloride denaturation of ribonuclease, lysozyme, $\alpha-$ chymotrypsin, and $\beta$-lactoglobulin. J. Biol. Chem. 249, 53885393.

Kjellson, A., Sethson, I. and Jonsson, B. (2003) Hydrogen exchange in a large $29 \mathrm{kD}$ protein and characterization of molten globule aggregation by NMR. Biochemistry 42, 363374.

Kutyshenko, V. P. and Prokhorov, D. A. (2003) Guanidine hydrochloride unfolding of a carbonic anhydrase molten globule. Mol. Biol. 37, 1055-1060.

Lopez-Arenas, L., Solios-Mendiola, S. and Hernandez-Arana, A. (1990) Estimating the degree of expansion in the transition state for protein unfolding: analysis of the $\mathrm{pH}$ dependence of the rate constant for caricain denaturation. Biochemistry 38, 15936-15943.

Martensson, L., Jonsson, B., Freskgard, P., Kihlgren, A., Svennson, M. and Carlsson, U. (1993) Characterization of folding intermediates of human carbonic anhydrase II: probing substructure by chemical labeling of $\mathrm{SH}$ groups introduced by site-directed mutagenesis. Biochemistry 32, 224-231.

Nozaki, Y. (1972) The preparation of guanidine hydrochloride. Methods Enzymol. 26, 43-50.

Privalov, P. L. (1979) Stability of proteins: small globular proteins. Adv. Prot. Chem. 33, 167-241.

Privalov, P. L. and Gill, S. J. (1988) Stability of protein structure and hydrophobic interaction. Adv. Prot. Chem. 39, 191-234.

Prokhorov, D. A., Kutyshenko, V. P. and Khristoforov, V. S. (2005) Carbonic anhydrase B interactions with water and urea. Mol. Biol. 39, 438-444.

Rendon, J. L. and Mendoza-Hernandez, G. (2001) Unfolding kinetics of glutathione reductase from cyanobacterium Spirulina maxima. Arch. Biochem. Biophys. 387, 265-272.

Sarraf, N. S., Saboury, A. A., Ranjbar, B. and Moosavi-Movahedi, A. A. (2004) Structural and functional changes of bovine carbonic anhydrase as a consequence of temperature. Acta Biochim. Polonica 51, 665-671.

Strohmeyer, E. A., Beckley, J. R. and Britt, B. M. (2002) Direct measurement of local and global contributions in the binding of coformycin to bovine adenosine deaminase. J. Enzyme Inhibit. 17, 77-86.

Uversky, V. N., Semisotnov, G. V., Pain, R. H. and Ptitsyn, O. B. (1992) 'All-or-none' mechanism of the molten globule unfolding. FEBS Lett. 314, 89-92.

Uversky, V. N. and Ptitsyn, O. B. (1996) Further evidence on the equilibrium "pre-molten globule state": four-state guanidinium chloride-induced unfolding of carbonic anhydrase B at low temperature. J. Mol. Biol. 255, 215-228.

Wang, C., Lascu, I. and Giartosio, A. (1998) Bovine serum fetuin is unfolded through a molten globule state. Biochemistry 37, 8457-8464.

Younvanich, S. S. and Britt, B. M. (2006) The stability curve of hen egg white lysozyme. Prot. Pept. Lett. 13, 769-772. 